\title{
Capacity Building of Project Beneficiaries and Performance of Community Based Conservation Projects: A Case of Laikipia Conservation Region Conservancies
}

\author{
Hussein Ndonye ${ }^{1}$, Angeline Mulwa, $\mathrm{PhD}^{2}$ \& Dorothy Ndunge Kyalo, $\mathrm{PhD}^{3}$ \\ ${ }^{1} \mathrm{PhD}$ Candidate, School of Open, Distance and Learning, University of Nairobi, Kenya \\ ${ }^{2}$ Senior Lecturer, School of Open, Distance and Learning, University of Nairobi, Kenya \\ ${ }^{3}$ Dean, School of Open, Distance and Learning, University of Nairobi, Kenya \\ * E-mail of the corresponding author: ndonyehussein@gmail.com
}

\begin{abstract}
This study determined the extent to which capacity building of project beneficiaries influenced performance of Community Based Conservation (CBC) projects in Kenya. Anchored on pragmatism, the study was guided by theory of change, participatory development and stakeholder theories. A cross sectional study design that adopted convergent mixed methods approach composed of quantitative and qualitative strands was utilized. Questionnaires, focused group discussions and document analysis were used to collect data from seven community conservancies dotting Laikipia Ecosystem. Quantitative data were analyzed using both descriptive and inferential statistics to test the nature and strength of the relationship between variables and to predict the dependent variable based on the independent variable. Qualitative data was analyzed using framework analysis to get themes and triangulate the quantitative results. Capacity building of project beneficiaries was found to positively and significantly influence performance of CBC projects $\left(\mathrm{r}=.727, \mathrm{R}^{2}=.529, \mathrm{~F}(1,237)=264.584\right.$ at $\left.\mathrm{p}=.001<.05\right)$. Furthermore, Welch's t-test showed that capacity building of project beneficiaries differed in the $\mathrm{CBC}$ project design of the sampled community conservancies as $\mathrm{F}=14.769 \mathrm{df}(6,231), \mathrm{p}=.001), \mathrm{t}=15.848 \mathrm{df}(6,72.291), \mathrm{p}=.001<.05$. The study recommends that design of $\mathrm{CBC}$ projects ought to include methods for the co-development of the capacity of local organizations, traditional institutions and the wider society. Furthermore, the capacity building should be designed to account for local political, economic and cultural facilitating environments.
\end{abstract}

Keywords: Conservation, Development, Capacity Building, Project Performance, Community Empowerment, Acceptance of Conservation, Sustainable Resource Use, Biodiversity Regeneration

DOI: $10.7176 / \mathrm{JESD} / 12-2-08$

Publication date: January $31^{\text {st }} 2021$

\subsection{Introduction}

The old philosophy toward wildlife conservation was a protectionist, a conservation in situ anchored on the premise that wildlife will survive and thrive when isolated from human contact. It was referred to as fortress conservation, characterised by fines and fences and did not only fail to safeguard biodiversity, but also alienated local communities raising ethical questions. It was territorial, land was set aside to be preserved in its natural condition and human activities limited to cases where a species was threatened or endangered (Newmark and Hough, 2000). Despite this strict policy, the problem of biodiversity loss especially in developing countries continued to exacerbate. With time, professionals in wildlife conservation however recognized that for long-term success in attempts to conserve biodiversity to be achieved, it was necessary for local community to be made to perceive conservation efforts as serving their economic and cultural interests. Conservationists became cognizant that culture, environment and socio-economic issues do not exist independently of one another but are inextricably intertwined, interdependent and can either be mutually supportive or mutually degrading if practiced unsustainably.

Since early 1970s, conservationists had continued to question the efficacy and morality of fortress conservation, arguing that with expert assistance, local communities were better placed to conserve biodiversity as they already relied on the very natural resources. Pursuant to that, over the last three decades, conventional narratives on conservation of biodiversity and local community development have been integrating. According to Campbell and Vainio-Mattila (2003), this paradigm shift was augmented with the publication of the Brundtland Commission Report in 1987 (WCED, 1987) which ushered the concept of sustainable development. Based on Brundtland Commission Report, development organizations started to increasingly incorporate environmental rhetoric into policy, whereas conservation organizations started acknowledging the development needs of local communities in biodiversity rich areas. Against that background, conservationists came to realization that fines and fences 
restrictions were harmful to local communities and their social well-being, and it fuelled individual and collective resistance (Dressler, Buscher, Schoon, Brockington et al., 2010). This protectionist approach of fines and fences undermined both conservation and development objectives.

\subsection{Statement of the Problem}

The efforts by development practitioners to mainstream ecological matters and those by conservation practitioners to recognize the plight of local communities culminated to new grass roots approaches variously called Integrated Conservation and Development Projects (ICDP). The main tenet of ICDP approach is that the projects seek to address biodiversity conservation objectives through the use of socio-economic investment tools. Literature recognizes many variants of the ICDP approaches based on the level of local community involvement. These variants are Community-Based Conservation (CBC), Community Based Natural Resource Management (CBNRM) initiatives, Ecotourism Enterprises, Alternative Livelihood Projects (ALPs) and Co-management (Brooks, 2017; Campbell and Vainio-Mattila, 2003). This study focused on CBC variant, and its consideration is warranted because of its popularity.

$\mathrm{CBC}$ projects were introduced to ensure bottom-up approach in the conservation of natural resources. Typically, the signature of $\mathrm{CBC}$ approaches is that they involve combinations of devolving control of natural resources, engaging communities, and linking conservation with local economic development. With local community at the center of wildlife conservation, the design of CBC projects must promote the capacity of local communities in order for the latter to innovate and sustain own solutions to problems in a way that aids them shape and exercise control over their economic, physical, and socio-cultural environments. Literature recognizes the importance of improving the capacity of locals, marginalized groups and government agencies in project implementation (Thomas, 2013). CBC projects are popular in Sub-Sahara and Southern African nations, however, there exists a dearth of empirical evidence on the effect that capacity building has on their effectiveness. It was based on that premise that this study set to determine the extent to which capacity building of project beneficiaries influenced performance of $\mathrm{CBC}$ projects in community conservancies in Laikipia ecosystem of Kenya.

\subsection{Test of Hypothesis}

In the study, emphasis was placed to determine extent to which capacity building of project beneficiaries influenced performance of $\mathrm{CBC}$ projects in Laikipia region. Pursuant to that, the researcher sought to test the following hypothesis.

$\boldsymbol{H}_{1}$ : There is a significant relationship between capacity building of project beneficiaries and performance of $C B C$ projects in Laikipia region.

Moreover, natural resource management is a complex undertaking and building the capacity of project beneficiaries is even more complex given the community fluidity and varying group dynamics. To this end, based on the stratified sampling that assumed the heterogeneity and diversity of individuals and groups of the members in the conservancies. The following hypothesis was tested to confirm this assumption.

$\boldsymbol{H}_{1:}$ Group means are different $(\mu A \neq \mu B)$

\subsection{Literature Review}

\subsection{Performance of CBC Projects}

In project management, different project managers have various definitions of performance depending on context, experience and knowledge. The UNDP (2009) defines performance of a project as the progress towards and achievement of intended results. Lester (2013) argues that the performance of a project is based on key performance indicators such as milestones to be met and especially the predetermined design, deliverables, and the planned production. There are suggestions that the performance should be studied from the perspective of project goals as well as the performance of the project processes. This study was about the performance CBC projects, which are in practice complex undertakings with multiple social, cultural, political and ecological factors that can affect performance. They are projects implemented in ecological communities comprising of complex networks of individuals that interact with each other and with the environment.

Complexity of issues change with geographic scope, types of stakeholders involved, differential interests and local contexts (Catacutan and Tanui, 2007). Project complexity negatively influences upon project management process and particularly on the project itself and therefore the performance of $\mathrm{CBC}$ projects is inched to how the complexity in them is addressed in the project design. CBC projects design ought to link conservation and local development. In addressing this linkage, the first step is the consideration of where the conservation and community needs 
intersect (Brown and Wyckoff-Baird, 1995). The intersection of conservation and community needs occurs at the optimum, a point where community interventions that result in conservation and wise use of the natural resources are possible. At the optimum, local communities view the future of their livelihoods as a function of their present practices and use of resources, they are likely to adopt more sustainable methods. This is because in the end, the performance and sustainability of integrated conservation initiatives adopting CBC model depends on positive impacts to the local community (Suich, 2013). This is because there exists a connection between conservation and socio-economic well-being of local communities.

The performance of a CBC projects is a multidimensional construct with human, economic and ecological dimensions. Dangi and Jamal (2016) agreed to this in their argument that in an integrated approach to sustainable community-based tourism, project performance should be seen through the lens of economic sustainability, social sustainability and environmental sustainability. CBC projects provide an incentive for the sustainable management of biodiversity resources as they link maintenance of ecosystems with poverty alleviation and livelihoods benefits for the local community. In recognition these multiple perspectives, according to Brooks, Waylen and Mulder (2012), the performance of CBC projects can be measured in four outcome domains of ecological, economic, attitudinal and behavioural outcomes. It was based on these concepts that in this study, CBC project performance was measured by ecological outcomes (community empowerment), attitudinal outcomes (acceptance of wildlife conservation), behavioural outcomes (sustainable resource use) and ecological outcomes (biodiversity regeneration).

\subsection{Capacity Building of Project Beneficiaries}

Building capacity of stakeholders in a community-based project is a key enabler of project implementation. Due to its importance in community development, capacity building is the pillar of participatory development and stakeholder theories. Koutra and Edwards (2012) described capacity building as imparting relevant knowledge, skills and competence and other elements required in the local community for empowerment. Building the capacities of local community is a precursor of development initiatives based on theory of change, since the ability of beneficiaries to handle project requirements is a necessary precondition of local change. CBC projects are meant to devolve conservation and rural development to the hands of the local community. This decentralization can only be successful if local community in conservation areas acquires the skills and capitals required for such an undertaking. Institutions and organizations that partner with local community to implement CBC projects need to provide an array of bridging services for enhancing empowerment and therefore the performance of those projects. Capacity building in $\mathrm{CBC}$ projects is about improving local community ability to learn and adapt through change. According to Koutra and Edwards (2012), capacity building in conservation projects is based on empowerment that targets four concepts, namely social, human, physical and financial capitals while Nthiga, Duim, VisserenHamakers and Lamers (2015); DFID (1999) saw capacity building for local development as comprising of the sustainable livelihood framework of five concepts; social, human, physical, financial and natural capitals. Sustainable livelihood framework feature is the focus on the local community assets at household level and the livelihood activities that can be realized using the assets. Targeting to leverage these issues is believed to empower the local community at household level and livelihood initiatives through capacity empowerment.

\subsection{Capacity Building of Project Beneficiaries and Performance of CBC Projects}

The devolvement of conservation and development via CBC projects calls for improvement of human capital as an enabler of project performance. Based on this premise, development of human capital by crafting capacity building where community members learn innovative ideas, develop skills, behaviours and attitudes and attain new competencies in prudent. For instance, human capacity development is critical for maximizing the potential of local community to conserve natural resources and spur local development. By building human capacities, local community individuals and groups could be empowered to grow abilities and fully participate in the conservation and development processes, which are the key aspects of a CBC project. According to Koutra and Edwards (2012), the improvement of human capital is a key element in achieving empowerment for economic progress and success. This is because improvement of human capital plays as a critical link in the theory of change and between conservation and development in a rural environment. The accumulated knowledge and skills increase productivity and earnings and change the attitudes and behaviour of local community towards conservation. This happens both at an individual and societal level by imparting conservation skills, giving ideas on management and innovative start-ups, all contributing to a chain of results that lead to conservation and development, the intended impacts of CBC projects.

Capacity building precedes socio-economic development, and this highlights the criticality of social capital capacity building in $\mathrm{CBC}$ project design. To this end, improving social capital has long been considered to 
contribute to socio-economic development. According to Parisi, Grice, Taquino and Gill (2002), social capital facilitated coordination and cooperation for mutual benefit. Furthermore, social capital is an indispensable resource that shapes individual action to realize positive local development and biodiversity outcomes. Qian, Barroso and Messer (2019) argue that social capital attends on the domain of "community" and comprises of the trust, social interactions and the reciprocity required to facilitate shared outcomes. Social capital comprises of close bonds among and between community members, local institutions, trust, sense of the belonging and networks. Further, O'Connell, Nasirwa, Carter, Farmer, et al. (2017) suggested the scaling up of current capacity building activities social footprint by factoring all sections of the community. Social capital is critical in CBC projects as it aligns community values, attitudes and behavior to conservation and development.

Integrated development and conservation initiatives achieve conservation by distracting labour away from unsustainable exploitation of biodiversity by means of alternative economic means. CBC model is based on conservation providing alternatives such as conservation enterprises; small and medium sized enterprises (SMEs) initiated to divert labour from negative wildlife resource use, the alternative livelihood projects. Financial capital to prop up local conservation enterprises which promote economically and environmentally sustainable alternatives to natural resource exploitation is important. Koutra and Edwards (2012) used a participatory research approach to demonstrate that lack of capacity building affected conservation project performance in Ghana. The authors investigated the impact of tourism enterprises and found that, after 15 years, the sector had not developed to significantly reduce poverty as expected. Lack of financial capacity building was found to be the main cause of tourism sector's inability to reduce poverty significantly and therefore dismal performance. The researchers underscore the essence of finance for conservation enterprises which are vital in linking conservation and development. Thus, it demonstrates that financial capacity building makes a substantial contribution towards the realization of socially responsible economic activities.

Land-use changes and degradation in community conservation areas pose direct threat to biodiversity because socio-economic practices can deplete natural capital, thereby undermining the resources needed to generate growth in the future. In light of this, a project design ought to include natural capital capacity building to conserve biodiversity. Such natural capital capacity building would include empowering the local community in reclaiming affected habitats and species and land use zonation. Nthiga et al. (2015) pointed that the importance of natural capital capacity building by highlighting zoning of the group ranches into settlement areas, grazing zones, conservation areas and initiating soil erosion control initiatives in Laikipia Ecosystem. Qian et al. (2019) used that sustainable livelihood framework to examine the plans to identify opportunities for future tourism planning and development. The authors employed directed content analysis method to analyse 10 comprehensive county plans. The results show that natural capital (composed of land/vegetation, wildlife and surface water was most frequently identified (59.8\%), thus affirming that natural capital formed the heart of all the other capitals. Natural capital is thus essential for all aspects of a local community economy and therefore key in reconciling conservation and development.

The sustainable livelihood framework puts emphasis on the physical capital as the community tools and assets that facilitate sustainable development through a production process. In CBC project set up, this could include infrastructure meant to benefit the general community, and help societies develop secure, stable, and sustainable economies. Such could be roads to enable transport, water pipeline and treatment, telecommunications and conservation related infrastructure such as hotels, bandas, tented camps and camping sites. In a study that drew on multiple sources of data, Parisi et al. (2002) used key informant survey approach to examine the extent to which local condition variation accounted for variation in local community efficacy for economic development. Based on multiple sources of data, the authors used logistic regression models to signify that capacity for community efficacy rested on four fundamental traits of community social capital, local physical infrastructure, human and monetary traits and community spatial traits. In addition, the authors argue that when physical infrastructure is availed to the community, the latter can facilitate the emergence of open and inclusive strategies of interplay in the direction of the development of a generalized interest. Although the study highlights on the importance of the capitals in community efficacy, the non-random sampling shakes the integrity of the results.

Indigenous knowledge systems of a community could be leveraged in $\mathrm{CBC}$ project design to build resilience of social and ecological systems, therefore linking conservation and local development. Ruiz-Mallen and Corbera (2013) reviewed 23 publications that comprised of 29 case studies to establish how local knowledge, CBC initiatives and resilience interrelated in social-ecological systems. The results of the review showed that traditional ecological knowledge had a vital role in enhancing the adaptive capacity of the local community to socialecological challenges in self-regulated CBC projects unlike in comanaged ones where government and experts play a more central role. This underscores the crucial role of social capacity building in CBC projects as a means 
to promote local community self-reliance in conservation and local development matters. The authors argue that local community relied on local experience and knowledge systems, cultural values, local institutions and community networks to cope with dynamic change and promote biodiversity conservation and local development. The paper does not however point to capacity building based on these issues as central to future design of CBC projects.

The nexus of $\mathrm{CBC}$ project design is to enhance the capacity of local community individuals, groups and institutions in making choices and transforming those choices into desired actions and outcomes. In a review, Brooks et al. (2012) showed project design; particularly building the capacity in local communities was associated with behavioural, attitudinal, ecological and economic performance in CBC initiatives. For instance, enhancing physical, financial and human capitals could bolster economic welfare and social capital will improve on attitude and behavioural outcomes. As for ecological performance, the building natural capital capacity was taken to be the required recipe. In a later article, Brooks, Waylen and Mulder (2013) further pointed out that behavioural success was most probable when the project invested in building capacity of local individuals, groups and institutions, adding that economic and ecological synergies were more likely for mature projects especially when capacity of individuals and institutions was enhanced. These results despite shedding light on the criticality of building capacity based on the sustainable livelihood framework emanate from a review and not an empirical study.

\subsection{Methodology}

\subsection{Study Area}

Laikipia region is found in Kenya's Great Rift Valley, tacked between Mount Kenya and the northern deserts, this savanna grassland ecosystem is rich in biodiversity. The area had been a patchwork of huge ranches, an important livestock district where one of Kenya's most encouraging conservation success stories are unfolding. According to Sundaresan and Riginos (2010) the region is a home of the highest diversity of large mammals than any other region in East Africa. Group ranches is a form of communal land ownership where by a group of households from the local community own and manage their land under the $\mathrm{CBC}$ approach. The conservancies in Kenya have become central in the evolution of new institutional arrangements for community involvement in conservation and tourism. Data for the study were collected from the community conservancies in the Laikipia ecosystem: Naibunga Upper, Naibunga Central, Naibunga Lower, Il Ngwesi and Lekurruki, Makurian and Kuri Kuri.

\subsection{Data Collection}

A cross sectional study design was adopted with data being collected from a predetermined population at just one point in time. The target population was geographically diverse and therefore, multistage sampling based on the hierarchical structure of the natural clusters within the population was adopted. First, the respondents were drawn from all the seven community conservancies identified to be constitutes in CBC models. Since the number of organizations under consideration was less than 200 , a census of the organizations was preferable rather than a sample (Watson, 2001) and therefore respondents of this study were drawn from all the 53 community-based organizations (CBOs) identified in the in the seven conservancies. Lastly, due to the assumed heterogeneity of the target population based on the conservancies, the study adopted stratified random sampling to target the members CBOs in the respective. It was assumed the representation of the population under study increased the efficiency of the study.

The target respondents comprised 911 CBO members involved in Livestock Works, Bead Works, Tourism Works, Bee Keeping and Moran Enterprises. The sample size was determined based on the formula proposed by Krejcie and Morgan (1970), which gave a sample size sufficient to provide accuracy to infer the findings to the population with confidence. See equation (1).

\section{$S=X^{2} N P(1-P 0) /\left(d^{2}(N-1)+X^{2} P(1-P)\right.$}

Where;

$\mathbf{S}=$ required sample size;

$\mathbf{X}^{\mathbf{2}}=$ the table value of chi-square for 1 degree of freedom at the desired confidence level (3.841);

$\mathbf{N}=$ the population size (911);

$\mathbf{P}=$ the population proportion (assumed to be 0.50 since this would provide the maximum sample size);

$\mathbf{d}=$ the degree of accuracy expressed as a proportion $(0.05)$

Therefore: $\mathrm{S}=3.841(911)(.50)(1-.50) / 0.052(911-1)+3.841(.50)(1-.50)=270.39$

Therefore, 270 respondents were selected for this study, out of which 238 responded. In the qualitative strand of 
the study, eight officials of the conservancies were purposively picked for the focussed group discussion and 11 conservancy documents comprising of annual conservancy reports, conservancy strategic plans, and progress reports were reviewed.

Convergent mixed method design was used in this study, specifically the parallel-databases variant (Creswell and Plano-Clark, 2011) where two parallel strands of quantitative and qualitative data collection were conducted independently and only brought together during the interpretation. Quantitative analysis comprised of descriptive statistics that included means, frequencies and standard deviations. Inferential statistics employed the use of Pearson's Product Moment of Correlation (r) to investigate and test the nature and strength of the relationship between variables and to predict the $\mathrm{CBC}$ project performance based on capacity building of project beneficiaries. Data from focussed group discussions and document reviews was sifted, charted and sorted in harmony with aprioristic set of categories viewpoint based on the indicators of the variables under study. Five steps were employed, that is; familiarization with the data, theme identification using indicators, indexing, charting, and mapping and then interpretation.

\subsection{Likert Scale as an Interval Measure}

In the quantitative strand of the study, a questionnaire with Likert Scale type questions was used. Based on Carifio and Perla (2008) it is perfectly appropriate to sum Likert items and analyse the summations parametrically, both univariately and multivariately. The Likert questions in this study were designed as a series of questions that when combined would measure a particular trait by calculating a composite mean from the Likert-type items. Jr and Boone (2012) advised that composite score for Likert scales should be analysed the interval measurement scale. Pursuant to these arguments, this study therefore assumed parametric statistics were sufficiently robust to yield largely unbiased answers that are acceptably close to "the truth" on analysing Likert scale responses from the questionnaire. Composite scores were used in analysis and decision rules after analysis of mean scores were guided by the logical equal levels of the score approximated to the first decimal point in line with equidistance arguments (Lantz, 2013). This study used one verbal anchor; $1=$ Not at all (NA); $2=$ To a little extent (LE); $3=$ To a moderate extent (ME); 4 = To a great extent (GE); $5=$ To a very great extent (VGE). The judgment rule in this study followed these arguments; Not at All for values lying between $1<\mathrm{NA}>1.8$; To a little extent for values between $1.8<\mathrm{LE}>2.6$; To a moderate extent for values between $2.6<\mathrm{ME}>3.4$; To a great extent for values between $3.4<\mathrm{GE}>4.2$; To a very great extent for values between 4.2<VGE $>5.0$. This creates a scale that has an equidistance of 0.8. Correlations coefficient was used to measure relationships. Decision rule followed Cohen (1988) suggested guidelines that Rvalue of between .10 to .29 means small or weak correlation; R-value of between .30 to .4 .9 means medium or moderate correlation and R-value of between .50 to 1.0 means large or strong correlation.

\subsection{Results and Discussion}

\subsection{Descriptive Analysis of Capacity Building of Project Beneficiaries}

The study adopted sustainable livelihoods framework that organizes the factors that constrain or enhance livelihood opportunities and have proved to bey key in linking conservation and development. The composite scores of capacity building based on the sustainable livelihoods' framework were as shown in Table 1.

Table 1: Descriptive Analysis of Capacity Building of Project Beneficiaries

\begin{tabular}{lccccc}
\hline Indicator & $\mathbf{n}$ & Min & Max & $\boldsymbol{\mu}$ & $\boldsymbol{\sigma}$ \\
\hline Human Capital Capacity Building & 238 & 1.67 & 5.00 & 3.8291 & .54064 \\
Social Capital Capacity Building & 238 & 2.00 & 5.00 & 3.8459 & .49808 \\
Financial Capital Capacity Building & 238 & 2.00 & 5.00 & 3.5473 & .63489 \\
Natural Capital Capacity Building & 238 & 2.25 & 5.00 & 3.8288 & .48211 \\
Physical Capital Capacity Building & 238 & 1.33 & 5.00 & 3.5336 & .78759 \\
\hline Composite Mean & $\mathbf{2 3 8}$ & $\mathbf{2 . 0 6}$ & $\mathbf{4 . 8 2}$ & $\mathbf{3 . 7 1 3 5}$ & $\mathbf{. 4 2 8 4 1}$ \\
\hline
\end{tabular}

$\mathrm{n}=$ Sample Size $\boldsymbol{\mu}=$ Mean $\boldsymbol{\sigma}=$ Standard Deviation

The results from Table 1, show that the composite scores of capacity building of project beneficiaries' indicators had means that ranged from $\mu=3.5336$ to $\mu=3.8459$, indicating that they were factored in the CBC project design to a great extent. Social capital capacity building had the highest mean $\mu=3.8459$ and standard deviation $\sigma=$ 0.49808 meaning that social capital capacity building was factored in the conservation projects to a great extent. Building of the social capital is meant to network, link project with local culture and institutions, promote harmony and therefore enable individuals and organizations in the community to change attitudes towards conservation and perform at a greater capacity as it is a catalyst of community development process. The design of the CBC projects 
was cognizant that human capital was important for imparting the knowledge, skills and welfare of the local community as human capital capacity building mean $\mu=3.8291$ and standard deviation $\sigma=0.54064$ indicate it was factored in project design to a great extent. Human capital capacity building is essential to CBC project performance as it the medium for human resource development, the latter being essential for community empowerment and innovation required in the alternative livelihood projects.

In $\mathrm{CBC}$ projects, development is not be considered separately from ecological processes, but are integrated to mutually enforce each other. Natural capital capacity building that ensures the ecological processes was important in the design of the projects as it was factored to a great extent $(\mu=3.8288 ; \sigma=0.48211)$. Natural capacity affords the community conservation and livelihood zones allowing species and habitat regeneration in addition to reclaiming rangelands for expand existing habitats. Financial capital capacity building $(\mu=3.5473 ; \sigma=0.63489)$ was factored in to the $\mathrm{CBC}$ project design to a great extent. This underscores its importance of habitat reclamation, rangeland seeding and zonation of settlement, grazing and conservation areas. A lack of sound financial capacity would be an impediment to local development since it is a source of capital to alternative livelihood initiatives meant to reduce pressure on the environment and ensure sustainable resource use. In linking conservation and development, physical capital is indispensable as it is a factor of production that supports conservation and the enterprises of alternative livelihoods. The results show that physical capital capacity building was factored in the $\mathrm{CBC}$ project design to a great extent $(\mu=3.5336 ; \sigma=0.78759)$. Physical capitals are critical in empowering local community by providing the means to economic activities and to conservation by availing required tools and equipment to ensure protection of biodiversity. Overall, with a mean $\mu=3.7135$ and standard deviation $\sigma=0.42841$, the analysis of the composite index of the indicators established that capacity building for project beneficiaries was factored in design of $\mathrm{CBC}$ projects to a great extent.

From the focused group discussions, human capacity was also developed by strengthening local managerial skills and abilities. The respondents pointed to technical training to conservancy management, rangers, youth and women. Once chairman said;

"We all undergo training on conservation and livelihood matters, our rangers trained by different institutions and some have been given Kenya Police Reserve status, the youth and women have received training on starting and managing enterprises and the most in our community have been trained on rangeland management training."

The analysis of the focused group discussions further found out that there was a considerable health support in the conservancies through construction and staffing of clinics. Results from the document analysis validated those from the survey and the group discussions. The document reviews pointed to a massive support of education of the conservation members children through school infrastructure, staffing, teacher training and bursaries. For instance, NRT (2017) indicated that 1,924 students received bursaries through their conservancies, a number that grew to 3,077 learners (NRT, 2019).

The survey results were endorsed by the focused group discussions and the secondary data from the reviewed documents. From the group discussions, it was found that there were training of the conservancy youth training on encroachment and mitigation of rustling to promote peace and cohesion. There were also youth and women benchmarking tours to well established conservancies to spur social learning in the conservancies. During the discussions, one manager reported that;

"Last month we took several youth members from my conservancy to Kalama Conservancy in Samburu

County to expose them so that we can try to walk the same path as the youths there."

Traditional ecological knowledge is heavily used in the conservation and livelihood initiatives. Document analysis corroborated about the benchmarking trips for youth and management for exposure in better established conservancies, community peace meetings to ensure cohesion and the empowerment of traditional institutions to ensure efficient local governance of resources. NRT (2019) reported that;

"There is inclusion of traditional council of elders in conservancy-led peace activities, and a greater focus on youth and herders in the peace process."

And that;

“...450 indigenous leaders in community conservancies have completed NRT's bespoke Leadership and Management Program since 2016."

The NRT (2018) listed the following social capacities enhanced to the local community: 420 youth trained on community welfare awareness; 850 women engaged in rangeland and peace initiatives training; 120 rangers trained were on human rights; and points on the empowerment of traditional institutions. Analysis results of 
focused group discussion found out that donors operated Conservancy Livelihoods Fund meant for conservancies to apply for, with proposals that reflected community priorities. One manager admitted that;

"We have revolving fund for enterprise capital for youth and women CBOs startups. In my conservancy, three million Kenya shillings (\$30,000) have been utilized for livelihood projects,"

Document analysis results concur with those of the group discussions. NRT (2019) reported that there existed community microfinance services and that the Conservancy Livelihood Fund had disbursed \$3 million (Ksh. 300 million) since 2015. The reviewed documents point to a well-coordinated market linkage for the local livelihood products. For instance, NRT (2018) reported that cattle fattened under livestock works are slaughtered in O1 Pejeta Conservancy (private conservancy) and sold to markets in Nairobi. NRT (2019) reports that;

"Bead Works uses its access to global markets to generate orders for beaded products at scale, then works with women in conservancies to meet these orders, improve their skills, increase income and take advantage of growth, income diversification and leadership opportunities."

The document review also pointed to concerted efforts by different conservation stakeholders to seek investors to exploit the gap in sustainable tourism development by investing in local tourism facilities. Based on the thematic framework analysis of the group discussions, there were efforts to prop up natural capital by rehabilitation of habitats through gullies healing, reseeding rangelands and controlling the spread of invasive species, specifically Acacia reficiens and Opuntia stricta. One conservancy manager said that;

"In our conservancy, we have so far rehabilitated 50 hectares of rangeland through gulley healing, reseeding and efforts to eradicate the stubborn Opuntia plant are proceeding in earnest."

Other natural capacities identified were planned re-introduction of wildlife species in habitats where they have been locally extinct, mainly black rhinoceros (Diceros bicornis) and hirola (Beatragus hunteri).

Document review corroborated the results, the analysis showed massive efforts in natural capital capacity building in rangeland rehabilitation. According to NRT (2019), over 3,000 conservancy members took part in activities to rehabilitate rangelands in 2019, kick-starting the restoration of over 7,000 hectares of what used to be productive grazing land for cattle and wildlife. NRT (2018) reported that land reclaiming through elimination of invasive species of plants where 1,478 hectares had been cleared of the land-degrading tree species in three conservancies. Other natural capital capacity building identified from the document review were seasonal and bunched grazing in the conservancies to allow habitat regeneration and planned establishment of sanctuaries for flagship wildlife species.

On physical capacity building, the researcher found out that there was renovation of tourism facilities in Naibunga Lower, Il Ngwesi and Lekurruki conservancies and planned development of new ones in Naibunga Upper and Naibunga Central conservancies. In addition, the respondents highlighted the support of donors in the development and maintenance of conservancy ranger facilities, that is, provision of rangers' houses and offices, equipment for rangers such as radios, cameras, Global Positioning System (GPS) gadgets. One manager said that;

"We have received a boost in terms of physical facilities in our conservancy. There has been renovation of two tourism facilities, we have received cameras for monitoring purposes and two ranger outposts constructed."

The group discussion analysis found that each conservancy had received a vehicle to help in management and patrols and the donors had agreed to foot the vehicle maintenance bill for the conservancies until the latter were self-reliant.

The document review found out that there was development of physical facilities in the conservancies such as tourism facilities, school and health facilities were renovated or newly constructed. To enhance local tourism, there were infrastructural developments like murram roads and that airstrips in the conservancies had been paved. NRT (2019) showed the investment in conservancy infrastructure in that 160 kilometres of roads and built or repaired five kilometres of airstrip in conservancies. This was meant to improve access to services, support business links and enable tourism access in some conservancies. This information was validated by Lekurruki Conservancy Management and Community Development Plan 2016-2020 which pointed out that physical capitals such as roads had been improved, the tourist facility, the Tassia Lodge had been renovated and a three-kilometre airstrip done. For biodiversity regeneration, NRT (2018) NRT had supplied women groups in one of the conservancies with 200 sacks of Cenchrus cilliaris grass seeds to help in rangeland regeneration.

\subsection{Comparison of Capacity Building of Project Beneficiaries Between the Conservancies}

To test the parity of Capacity Building of Project Beneficiaries means of the independent samples, a one-way 
between-groups ANOVA was conducted. Respondents were divided into seven groups according to their conservancies. To carry out the comparison of means, the hypotheses for the test were the following:

$\boldsymbol{H}_{\boldsymbol{o}}$ : Group means are identical $(\mu A=\mu B)$

$\boldsymbol{H}_{1}:$ Group means are different $(\mu A \neq \mu B)$

Table: 2: Comparisons of Capacity Building of Project Beneficiaries in the Conservancies

\section{Capacity Building of Project Beneficiaries}

\begin{tabular}{llllll}
\hline & Sum of Squares & df & Mean Square & F & Sig. \\
\hline Between Groups & 12.060 & 6 & 2.010 & 14.769 & .000 \\
Within Groups & 31.438 & 231 & .136 & \\
\hline Total & $\mathbf{4 3 . 4 9 8}$ & $\mathbf{2 3 7}$ & & \\
\hline Robust Tests of Equality of Means & \multicolumn{5}{l}{$\begin{array}{l}\text { Welch Statistic }=15.848 \\
\text { df } 1=6, \text { df } 2=72.291 ; \mathrm{p}=.001<0.05\end{array}$}
\end{tabular}

The results in Table 2 reveal that there was a statistically significant difference between the means of the groups as determined by one-way ANOVA, $\mathrm{F}=26.703 \mathrm{df}(6,231), \mathrm{p}=.001)$. The results of the Welch two-samples t-test also showed that there was statistically significant difference between the group means, $t=31.009 \mathrm{df}(6,72.291)$, $\mathrm{p}=.001<.05$. This provides a ground to reject the null hypothesis $\left(\boldsymbol{H}_{\boldsymbol{0}}\right)$ and conclude that not all group means were equal. This in an indication that capacity building of project beneficiaries was not factored uniformly in the CBC project design in all the sampled community conservancies. The means for groups in homogeneous subsets are displayed in Figure 1.

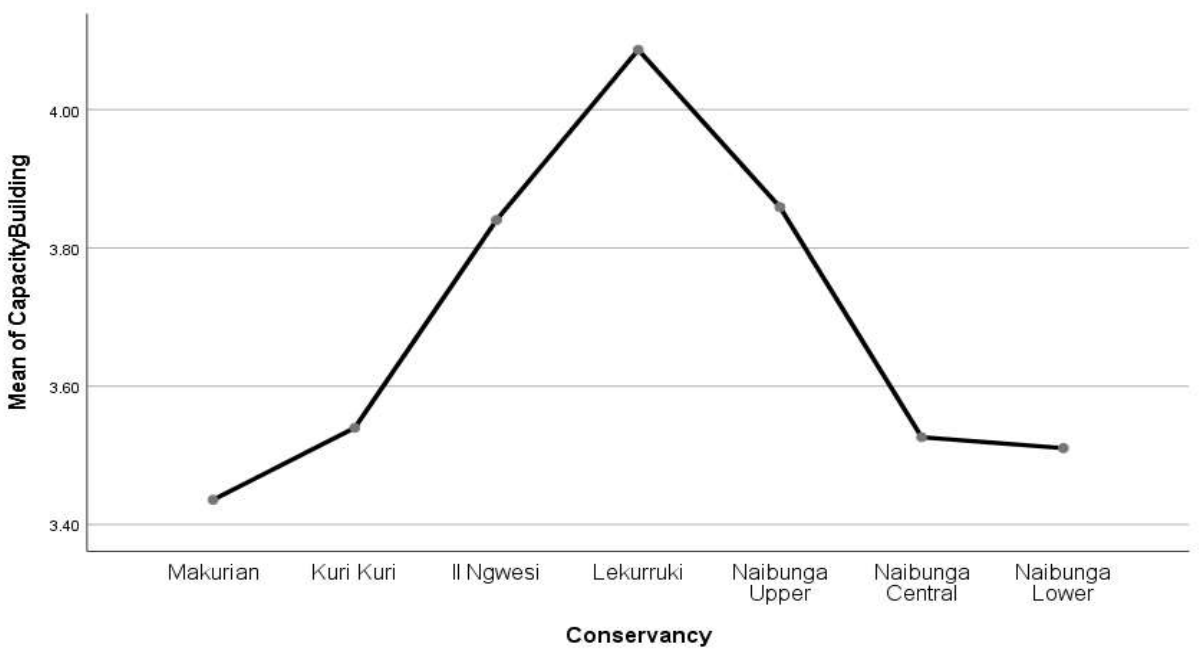

Figure 1: Mean Plot of Capacity Building of Project Beneficiaries in the Conservancies

Figure 1 shows three subsets, in the first set, Lekurruki conservancy had the highest rated capacity building of project beneficiaries $(\mu=4.0865)$. The second rated subset in capacity building of project beneficiaries was that of Naibunga Upper and Il Ngwesi conservancies, with means $\mu=3.8590$ and $\mu=3.8403$ respectively. The last subset in capacity building of project beneficiaries was Kuri Kuri $(\mu=3.5398)$, Naibunga Central $(\mu=3.5262)$, Naibunga Lower $(\mu=3.5104)$ and Makurian $(\mu=3.4357)$. The inherent complexities in the different conservancies could explain the differences in the level of capacity building factored in the project design. Catacutan and Tanui (2007) pointed out that complexity changes with geographic scope, types of stakeholders involved, differential interests and local contexts.

\subsection{Relationship between Capacity Building of Project Beneficiaries and Performance of CBC Projects}

Correlation analysis using Pearson's Product Moment technique was done to determine the relationship between capacity building of project beneficiaries and the performance of CBC projects. It was meant to identify the strength and direction of the association between the capacity building of project beneficiaries and the performance of CBC projects. The results are summarized in Table 3.

According to Table 3, there is a strong and positive relationship ( $\mathrm{r}=.727)$ between capacity building of project 
beneficiaries and performance of $\mathrm{CBC}$ projects. Furthermore, the correlation between the two variables is statistically significant at $\mathrm{p}=0.01<0.5$. These results mean that capacity building of project beneficiaries was perceived to contribute to performance of $\mathrm{CBC}$ projects to a great extent.

Table 3: Capacity Building of Project Beneficiaries and Performance of CBC Projects

\begin{tabular}{llc}
\hline & & Composite Capacity Building \\
\hline Performance of CBC Projects & Pearson Correlation & $.727^{* *}$ \\
& Sig. (2-tailed) & .000 \\
& $\mathrm{~N}$ & 238 \\
\hline
\end{tabular}

** Correlation is significant at the 0.01 level (2-tailed).

4.4 Test of Hypothesis

The influence of Capacity Building of Project Beneficiaries and Performance of CBC Projects was further determined using simple linear regression and the following hypothesis was tested.

$\boldsymbol{H}_{0}$ : There no significant relationship between capacity building of project beneficiaries and performance of community-based conservation projects in Laikipia region.

$\boldsymbol{H}_{1}$ : There is a significant relationship between capacity building of project beneficiaries and performance of community-based conservation projects in Laikipia region.

In order to test this hypothesis regression analysis was run to estimate the relationships between a composite index of performance of $\mathrm{CBC}$ projects and the composite index of capacity building of project beneficiaries. This was to realise a statistical model to predict performance of the $\mathrm{CBC}$ projects surveyed in terms of the capacity building of the project beneficiaries. The linear regression model was;

$\mathbf{Y}=\mathbf{a}+\boldsymbol{\beta}_{\mathbf{1}} \mathbf{X}_{\mathbf{C}}+\mathbf{e}$

Where: $\quad \mathrm{Y}=$ Performance of $\mathrm{CBC}$ Projects

$$
\begin{aligned}
& a=\text { Constant } \\
& \beta_{1}=\text { Beta coefficient } \\
& X_{C}=\text { Capacity building of the project beneficiaries } \\
& e=\text { error term }
\end{aligned}
$$

\begin{tabular}{|c|c|c|c|c|}
\hline Model & Unstandardized Coefficients & $\begin{array}{c}\text { Standardized } \\
\text { Coefficients }\end{array}$ & $\mathbf{t}$ & p-value \\
\hline & Std. Error & Beta & & \\
\hline (Constant) & .177 & & 4.984 & .000 \\
\hline Capacity Building & .047 & .727 & 16.266 & .000 \\
\hline \multicolumn{5}{|c|}{$\begin{array}{l}\text { Dependent Variable: Performance of CBC Projects } \\
\text { Predictors: (Constant), Capacity Building of Project Beneficiaries }\end{array}$} \\
\hline $\begin{array}{l}R=.727 \\
R \text { Square }=.529 \\
F(1,237)=\mathbf{2 6 4 . 5 8 4}\end{array}$ & $001<.05$ & & & \\
\hline
\end{tabular}

Table 4 presents summary results of the regression analysis.

Table 4: Influence of Capacity Building of Project Beneficiaries on Performance of CBC Projects

Results in Table 4 show that $\mathrm{R}^{2}=0.529$ suggesting that 52.9 percent of variation in performance of CBC projects is explained by capacity building of project beneficiaries which means that 46.1 percent of variation is explained by other factors that are not in the model. Further, a beta value of 0.771 signals that a unit increase of capacity building of project beneficiaries contributes to 77.1 percent increase in performance of $\mathrm{CBC}$ projects. Overall, the model is statistically significant at $p=.001<.05$. The $F$ ratio was significant in view of the fact that $F(1,237)$ $=264.584, \mathrm{p}=.001<.05$. This indicates that there was a statistically significant influence by capacity building of project beneficiaries on the performance of $\mathrm{CBC}$ projects. This provides enough evidence to reject the null hypothesis $\left(\boldsymbol{H}_{0}\right)$ for the entire population and conclude that capacity building of project beneficiaries had statistically significant influence on performance of $\mathrm{CBC}$ projects in Laikipia region at 0.05 level of significance. Using the statistical findings, the regression model can be substituted as follows;

$\mathrm{Y}=\mathbf{0 . 8 8 3}+\mathbf{0 . 7 7 1} \mathrm{C}+\mathbf{0 . 1 7 7}$

Where: $\mathbf{Y}=$ Performance of $\mathrm{CBC}$ Projects 


\section{$\mathbf{C}=$ Capacity building of project beneficiaries}

Based on theory of change, it was conceptualized that when capacity building of project beneficiaries enhances $\mathrm{CBC}$ project performance by changing the utilization of natural resources by local community. One strategy used in the design of $\mathrm{CBC}$ projects was to focus on conservancies and build from their existing capacities in order to improve capacities for the livelihood projects. These were harnessing culture such as bead works, livestock rearing, bee keeping and so on. The results corroborate those of O'Connel et al. (2017) that to accomplish their conservation goals, then individuals, community groups and organizations need to acquire different capacities in terms of diversity of knowledge, information and skills. The acquired skills were the precursor to the conservation enterprises and startups, leading to incomes and therefore empowerment.

The study established that capacity building was important in establishing alternative sustainable livelihoods that the local community could depend on, leading to reduced reliance on environment and therefore performance of $\mathrm{CBC}$ projects through the achievement of sustainable resource use. This is in line with Roe, Day, Booker, Zhou, Allebone-Webb et al. (2014) who posited that alternative livelihood projects were avenues for reducing local level threats to habitats, species, or resources of conservation concern. The study established that the $\mathrm{CBC}$ project design involved substitution of livelihood strategies that harm the biodiversity target through unsustainable exploitation with initiatives of a negligible or lesser, impact on the same target such as ecotourism. In other cases, the CBC project design involved building capacities of an alternative occupation such as bead works and beekeeping to take away labor from unsustainable use of biodiversity resources. The study found that the $\mathrm{CBC}$ project design involved building capacities to encourage a substitute method of resource exploitation has a lower impact on biodiversity than the original method and therefore ecological performance of $\mathrm{CBC}$ projects is realized. These were practices like zoning the community areas to conservation areas and grazing areas and bunched grazing as opposed to traditional free-range approach.

It was established that in the $\mathrm{CBC}$ project design, capacity building paid attention to cultural values. The results show that the projects sought to strengthen the capacities of local stakeholders in the application and use of indigenous knowledge in conservation. Thomas (2013) found that identification and use of local knowledge and skills is a vital step towards the performance of $\mathrm{CBC}$ projects. The capacity building of the project beneficiaries mobilized traditional ecological knowledge, innovations and practices that were relevant to the conservation and sustainable use of biodiversity. The design of the CBC projects used capacity building to combine indigenous knowledge of natural resource management and scientific expertise to moot better practices and approaches to conservation, for instance, bunched grazing and cattle fattening in livestock works. This led to attitude and behavioral change of the local community towards wildlife conservation.

\subsection{Conclusions and Recommendations}

The study also sought to establish the influence of capacity building of project beneficiaries on the performance of $\mathrm{CBC}$ projects. The indicators were based on the sustainable livelihood framework and the extent of building of social, financial, human, natural and physical capital in the projects was investigated. The study concluded capacity building of project beneficiaries had a significant positive influence on performance of $\mathrm{CBC}$ projects. In this regard, the improvement of capacity building of project beneficiaries is critical. Attention to local community capacities based on sustainable livelihoods approach should form a cornerstone in conservation project design thinking.

$\mathrm{CBC}$ projects are designed to encourage conservation by means of distraction. That distraction comes in the shape of the alternative livelihood projects targeting to provide alternatives to unsustainable exploitation and take away idle labour that could have been involved in conservation vices. Therefore, design of CBC projects ought to include methods for the co-development of the capacity of local CBOs, traditional institutions and the wider society. Furthermore, the capacity building should be designed to account for local political, economic and cultural facilitating environments. Furthermore, there is need for diversification of livelihoods in conservancy areas and capacity building of project beneficiaries is ideal to remedy the situation.

\section{References}

Brooks, J. (2017). Design Features and Project Age Contribute to Joint Success in Social, Ecological and Economic Outcomes of CBC Projects, Conservation Letters, 10(1), 23-32.

Brooks, J., Waylen, K.A. \& Mulder, M.B. (2012). How National Context, Project Design, and Local Community Characteristics Influence Success in CBC Projects, Proceedings of the National Academy of Sciences 109(52). 
Brooks, J., Waylen, K.A. \& Mulder, M.B. (2013). Assessing CBC Projects: A Systematic Review and Multilevel Analysis of Attitudinal, Behavioral, Ecological and Economic Outcomes, En. Evid., 2(2).

Brown, M. \& Wyckoff-Baird, B. (1995). Designing Integrated Conservation and Development Projects, WWFUS Biodiversity Support Program, Washington, DC.

Campbell, L.M. \& Vainio-Mattila, A. (2003). Participatory Development and Community-Based Conservation: Opportunities Missed for Lessons Learned? Human Ecology, 31(3), 417-437.

Carifio, L. \& Perla, R. (2008). Resolving The 50-Year Debate Around Using and Misusing Likert Scales, Medical Education, 42(12), 1150-1152.

Catacutan, D. C. \& Tanui, J. K. (2007). Engaging Stakeholders in Integrated NRM: Approaches and Guidelines from Land Care, World Agroforestry Centre, www.worldagroforestry.org/.

Creswell, J. W., \& Plano Clark, V. L. (2011). Designing and Conducting Mixed Methods Research (2 ${ }^{\text {nd }}$ Ed.). Thousand Oaks, CA: Sage.

Dangi, T.B. \& Jamal, T. (2016). An Integrated Approach to "Sustainable Community-Based Tourism", Sustainability, 8(475), doi:10.3390/su8050475.

DFID (1999). Sustainable Livelihoods Guidance Sheets, DFID, London.

Dressler, W., Buscher, B., Schoon, M., Brockington, D., Hayes, T. \& Kull, C. et al. (2010). From Hope to Crisis and Back Again? A Critical History of the Global CBNRM Narrative. Environmental Conservation. 37.5 - 15. 10.1017/S0376892910000044.

Jr, H.N. \& Boone, D.A. (2012). Analyzing Likert Data. Journal of Extension. 50.

Koutra, C. \& Edwards, J. (2012). Capacity Building through Socially Responsible Tourism Development: A Ghanaian Case Study, Journal of Travel Research, 51(6), 779-792.

Krejcie, R. V. and Morgan, D. W. (1970). Determining Sample Size for Research Activities. Educational and Psychological Measurement, 30, 607-610.

Lantz, B. (2013). Equidistance of Likert-Type Scales and Validation of Inferential Methods Using Experiments and Simulations. Electronic Journal of Business Research Methods (11). 16-28.

Lester, A. (2013). Project Management, Planning and Control: Managing Engineering, Construction and Manufacturing Projects to PMI, APM and BSI Standards: $6^{\text {th }}, 1-567$.

Nelson F. \& Agrawal, A. (2008). Patronage or Participation? CBNRM Reform in Sub-Saharan Africa, Development and Change, 39(4), 557-585.

Newmark, W.D. \& Hough, J. (2000). Conserving Wildlife in Africa: Integrated Conservation and Development projects and Beyond, Bioscience, 50(7), 585-592.

NRT (2017). State of Wildlife Conservancies in Kenya Report, https://www.nrt-kenya.org/document-library

NRT (2018). State of Wildlife Conservancies in Kenya Report, https://www.nrt-kenya.org/document-library

NRT (2019). State of Wildlife Conservancies in Kenya Report, https://www.nrt-kenya.org/document-library

Nthiga, R.W., Duim, R.V., Visseren-Hamakers, I.J. \& Lamers, M. (2015). Tourism Conservation Enterprises for Community Livelihoods and Biodiversity Conservation in Kenya, Development Southern Africa, 32(3), 407-423.

O’Connell, M.J., Nasirwa, O., Carter, M., Farmer, K.H., Appleton, M., et al. (2017). Capacity Building for Conservation: Problems and Potential Solutions for Sub-Saharan Africa, Oryx, 1-11.

Parisi, D., Grice, S., Taquino, M. \& Gill, D.A. (2002). Building Capacity for Community Efficacy for Economic Development in Mississippi, Journal of the Community Dev. Society, 33(2), 19-38.

Qian, X., Barroso, F. \& Messer, C. (2019). Addressing Tourism in County-Level Planning Documents: A Pilot Application of The Community Capitals Framework, International Journal of Tourism Policy, 9, 282-299. doi.10.1504/IJTP.2019.10027254.

Roe, D., Day, M., Booker, F., Zhou, W., Allebone-Webb, S., Kümpel, N. et al. (2014). Are Alternative Livelihood Projects Effective at Reducing Local Threats to Specified Elements of Biodiversity and/or Improving or Maintaining the Conservation Status of Those Elements? A Systematic Review Protocol, Environmental Evidence, 3. 1-8. doi10.1186/2047-2382-3-6. 
Ruiz-Mallén, I. \& Corbera, E. (2013). Community-Based Conservation and Traditional Ecological Knowledge: Implications for Social-Ecological Resilience. Ecology and Society 18(4)12.

Suich, H. (2013). Evaluating the Household Level Outcomes of Community Based Natural Resource Management: The Tchuma Tchato Project and Kwandu Conservancy. Ecology and Society 18(4), doi.org/10.5751/ES-05875-180425.

Sundaresan, S. R. \& Riginos, C. (2010). Lessons Learned from Biodiversity Conservation in The Private Lands of Laikipia, Kenya, Great Plains Research: A Journal of Natural and Social Sciences, 20 (Spring), 17-27.

UNDP (1997). Human Development Report 1997, United Nations Development Program, New York.

UNDP (2009). Handbook on Planning, Monitoring and Evaluating for Development Results, United Nations Development Program, New York.

Walzer, N. \& Merrett, C.D. (2002). Collaboration, New Generation Cooperatives and Local Development, Journal of the Community Development Society, 33(2), 19-38.

Watson, Jeff (2001). How to Determine a Sample Size: Tipsheet \#60, University Park, PA: Retrieved from http://www.extension.psu.edu/evaluation/pdf/TS60.pdf

WCED (1987). Our Common Future, Oxford University Press, Oxford. 